\title{
LA DEMOCRACIA INCONCLUSA: \\ DERECHOS FUNDAMENTALES, INSTITUCIONES POLÍTICAS Y RENDIMIENTOS GUBERNAMENTALES EN ECUADOR (1979-2008)
}

\author{
The Unfinished Democracy: Fundamental Rights, \\ Political Institutions, and Government Performance in Ecuador \\ (1979-2008)
}

\section{SANTIAGO BASABE-SERRANO}

Centro de Investigaciones de Política y Economía (CIPEC)

\section{SIMÓN PACHANO}

Facultad Latinoamericana de Ciencias Sociales, FLACSO Ecuador

\author{
ANDRÉS MEJÍA ACOSTA \\ Instituto de Estudios para el Desarrollo (IDS)
}

\begin{abstract}
RESUMEN
Luego de tres décadas de gobiernos elegidos por sufragio universal, Ecuador presenta serias deficiencias en las dimensiones constitucional y social de la democracia. Si bien existen elecciones libres y limpias, el irrespeto a las instituciones democráticas, la ausencia de un Estado de Derecho consolidado y marcadas asimetrías sociales dan cuenta de los deficitarios rendimientos del régimen. A pesar de que el presidente Correa ha contado con todas las condiciones para propiciar un cambio en las formas de gobernar el país, las viejas prácticas caudillistas, la violación de la ley y el clientelismo son aún rasgos esenciales de la vida política en el Ecuador.
\end{abstract}

Palabras clave: Ecuador, democracia, instituciones políticas, partidos políticos, elecciones, gobernabilidad, Estado de Derecho.

\begin{abstract}
After three decades of governments elected by universal vote, Ecuador shows serious deficiencies in constitutional and social dimensions of democracy. Although Ecuador holds free and transparent elections, the disrespect to democratic institutions, the weak rule of law, and strong social asymmetries, characterize the low performance of its democratic regime. Though President Correa has had all conditions to change the dynamics of political system, the caudillismo, the disrespect for the law, and patronage are essential features of political life in Ecuador yet.
\end{abstract}

Key words: Ecuador, democracy, political institutions, political parties, elections, governance, Rule of Law. 


\section{INTRODUCCIÓN}

Durante los últimos treinta años de democracia ecuatoriana (1979-2009), dos factores influyeron de forma decisiva sobre los mediocres rendimientos del régimen. Por un lado, la ausencia de un sistema de partidos y electoral consolidados alrededor de programas ideológicos y votantes leales. Por otro, un entramado institucional deficiente en cuanto a la tutela de los derechos ciudadanos, el equilibrio entre poderes y la sanción justa y oportuna a quienes rompen los acuerdos sociales o políticos. Como consecuencia de ello, tres presidentes fueron cesados anticipadamente $(1997,2000,2005)$, abriéndose así el camino a una nueva etapa en la vida política del país.

Bajo dicho escenario, este artículo explora el trayecto asumido por la democracia ecuatoriana en sus tres décadas de vigencia. Para ello, la discusión se organiza alrededor de cuatro secciones. La primera explora algunas dimensiones que se consideran relevantes para el estudio comparado de la democracia en la región, otorgando especial atención a tres aspectos. Por un lado, la incapacidad del sistema electoral para representar efectivamente las preferencias ciudadanas. Luego, el conflicto permanente entre los diferentes poderes del Estado; y, finalmente, la influencia directa o indirecta de militares y otros actores no electos en el proceso de toma de decisiones. La segunda hace un breve análisis del contexto en el que surge el presidente Rafael Correa y los factores que explicarían sus repetidos triunfos electorales. Con ello, en la tercera parte se evalúa si las reformas adoptadas en la nueva Constitución tienden a fortalecer los incentivos hacia la cooperación política y si tales mecanismos ayudarán a enfrentar los problemas de desgobierno existentes en el país. La cuarta sección provee algunas conclusiones.

\section{LAS DIMENSIONES DE LA DEMOCRACIA}

Para la evaluación del régimen democrático ecuatoriano, en esta parte se analizan algunas variables relacionadas tanto al cumplimiento de determinados procedimientos políticos como a la evaluación de los rendimientos generados en otras esferas de interés. Específicamente, pasamos revista a las dimensiones electoral, constitucional y económico-social. Dicha estrategia, asumida en aras de mantener cierta homogeneidad con los trabajos que conforman este número, sin embargo conlleva una merma en el análisis exhaustivo de otros aspectos clave para la vida democrática del país. Por ello, en el siguiente numeral se ofrece una exploración más amplia sobre algunos puntos coyunturales que resultan de trascendental importancia para el caso de Ecuador.

\section{a. Democracia electoral}

Dentro de la dimensión electoral de la democracia se incluyen algunas subcategorías relacionadas a la vigencia y efectivo cumplimiento de aquellos derechos políticos que, por su trascendencia, constituyen el punto de partida para la evaluación del régimen democrático. En esencia, consideramos la amplitud del derecho al voto, la pureza de 
los procesos eleccionarios, la posibilidad real de la ciudadanía de elegir y ser elegida; $y$, finalmente, la capacidad formal y fáctica de las autoridades electas para ejercer acciones de gobierno.

\section{Respeto del derecho al voto}

En Ecuador no existen restricciones significativas para el ejercicio del voto. Se lo reconoce como un derecho y un deber -debido a su carácter obligatorio-, aunque es facultativo para los ciudadanos entre 16 y 18 años, militares y policías, y para las personas mayores de 65 años. No es necesaria la inscripción de los electores pues el registro electoral se genera automáticamente desde el Registro Civil. En ese aspecto, y a pesar de que las evaluaciones realizadas sobre la calidad del padrón electoral han detectado algunos errores, estos no tienen la magnitud necesaria para hablar de una violación al ejercicio del derecho citado. No obstante, hasta 1979 los iletrados fueron excluidos de la posibilidad de sufragar, con lo que se marginó del voto a buena parte de la población indígena, entre la que se concentraban los mayores índices de analfabetismo. Con el retorno a la democracia tal barrera se eliminó, otorgándose en tales casos un voto opcional o facultativo.

En cuanto al voto de las mujeres, este se encuentra reconocido explícitamente en Ecuador desde 1929, aunque en años anteriores -1906- podía ya ser ejercido al no existir disposiciones en sentido contrario. Además, desde el año 2000 existen normas que establecen incrementos progresivos de cuotas femeninas para la conformación de las listas de candidaturas -artículos 58 y 59 de la Ley de Elecciones-, con lo que a la fecha hay una participación electoral paritaria y alterna de hombres y mujeres. ${ }^{1}$ Por otro lado, si bien no existe una cuota fija de representación para la población indígena, las distintas agrupaciones políticas con reivindicaciones étnicas han conseguido una fuerte presencia en cargos de elección popular -diputaciones, alcaldías, concejalías y consejerías-. De hecho, los espacios de poder alcanzados por estas minorías guardan relación e incluso superan al 6,83\% de población indígena que tiene el país (INEC, 2009). ${ }^{2}$

\section{Elecciones limpias y libres}

A pesar de que los organismos de gestión y control de las elecciones -Tribunal Supremo Electoral y tribunales electorales provinciales- están conformados por representantes de partidos políticos, no se han presentado casos comprobados de fraude. ${ }^{3}$ Acorde a los informes de diversas misiones de observación electoral -Organización de Estados Americanos, Unión Europea, Centro Carter, entre otras-, si bien se han verificado

1 Las normas citadas establecían originalmente que un 30\% de los integrantes de las listas sean mujeres, debiendo incrementarse dicho porcentaje en cada elección en cinco puntos porcentuales hasta llegar al 50\%.

2 Esta es la cifra oficial de ciudadanos y ciudadanas autodefinidos como indígenas en el VI Censo de Población y V de Vivienda realizado en el año 2001.

3 Con la nueva Constitución Política el diseño institucional de los organismos de control y justicia electoral varió. 
anomalías menores, estas no han afectado los resultados finales. Por consiguiente, en términos organizativos y de logística, las elecciones ecuatorianas pueden ser calificadas como limpias. Sin embargo, en lo relacionado al financiamiento de las campañas electorales pueden encontrarse algunas evidencias que niegan la transparencia total de las elecciones. Así, a pesar de que desde el año 2000 está vigente la Ley Orgánica de Control del Gasto Electoral y de la Propaganda Electoral, las autoridades han sido incapaces de imponer sanciones a los partidos y las organizaciones políticas que violan los límites establecidos.

Por otro lado, no se encuentran restricciones legales que afecten la decisión del voto de las personas. Tampoco se han generalizado las medidas de fuerza como práctica para violentar la decisión ciudadana o -como ocurrió durante buena parte del siglo XX-para evitar la concurrencia de los potenciales adversarios a las mesas de votación. Esas prácticas han sido superadas, como también la intervención de actores poderosos -como la Iglesia Católica o las Fuerzas Armadas- que podían incidir decisivamente en las preferencias de los ciudadanos. Sin embargo, se puede considerar que las formas clientelares, generalizadas en la política y de manera especial en los procesos electorales, constituyen formas de coerción que limitan la decisión electoral libre. El intercambio de votos por favores, la entrega de regalos en los actos de campaña, el incremento de programas asistenciales en épocas electorales e incluso el pago directo por el voto son algunos ejemplos de las prácticas anotadas.

\section{Autoridades elegidas y con capacidad para gobernar}

El régimen presidencial en Ecuador establece un mandato fijo de cuatro años para el jefe de gobierno, quien al mismo tiempo es jefe de Estado. La elección del primer mandatario se realiza a través de un sistema de mayoría por segunda vuelta ${ }^{4}$ y generalmente ha coincidido con las contiendas legislativa y seccional. ${ }^{5}$ Formalmente, los gobernantes tienen independencia en su mandato y por ende son autónomos en su capacidad para gobernar; sin embargo, las distintas administraciones no han estado exentas de las presiones de diversos grupos económicos y sociales. Tales constreñimientos se hicieron evidentes, por ejemplo, en las preasignaciones presupuestarias que beneficiaban a las FF.AA. con una porción de las rentas petroleras o en la participación directa de grupos empresariales en la fijación de tasas de interés y arancelarias a través de la Junta Monetaria (Conaghan, 1995).

A pesar de que estos grupos afectaron la dirección de las políticas públicas, hay otros factores que también deben considerarse para entender el incremental proceso de

4 Si en la primera vuelta electoral el candidato ganador obtiene más del $40 \%$ de los votos válidos y marca una diferencia de al menos diez puntos porcentuales respecto al segundo, el ballotage no es necesario. Tal escenario se verificó en el reciente triunfo del presidente Rafael Correa.

5 La excepción a esta regla se dio entre 2000 y 2006. En efecto, la remoción del presidente Bucaram en 1997 y la convocatoria a nuevas elecciones presidenciales rompió la sincronía entre elecciones nacionales y subnacionales. Este equilibrio se recuperó con las elecciones generales de abril de 2009. 
inestabilidad institucional observado desde 1996 y que se halla materializado en las inconstitucionales salidas de los ex presidentes Bucaram (1997), Mahuad (2000) y Gutiérrez (2005). Si bien cada uno de estos eventos tiene particularidades, en todos se observa una intervención legislativa para legitimar la remoción presidencial. Aunque este "voto parlamentario de desconfianza" fue instrumental para romper los bloqueos políticos que antecedieron a las crisis, tales decisiones se tomaron a costa de violar dos principios fundamentales de los presidencialismos: la independencia del Poder Ejecutivo y el respeto al período presidencial (Mejía Acosta y Polga Hecimovich, 2009).

\section{b. Democracia constitucional}

Para analizar la dimensión de la democracia constitucional se han considerado tanto los rendimientos de los poderes del Estado como sus interacciones. Además se plantea una revisión del comportamiento de otros actores, como las Fuerzas Armadas, que sin poseer capacidades formales de veto han ejercido un papel decisivo en las dinámicas asumidas por la democracia ecuatoriana. Posteriormente, una revisión del tratamiento otorgado a derechos civiles y políticos cierra el presente acápite.

\section{Independencia del Ejecutivo y el Legislativo}

Uno de los problemas recurrentes de la democracia ecuatoriana ha sido la conflictiva relación entre los poderes Ejecutivo y Legislativo. Por ello, durante tres décadas los presidentes han recurrido a un amplio repertorio de incentivos, amenazas, prerrogativas y negociaciones, formales e informales, para extraer apoyo de una intensa y fragmentada oposición representada en el Congreso. No obstante, la denominada pugna de poderes siempre estuvo presente, retrasando la aprobación de políticas de ajuste, generando incertidumbre e inestabilidad en otras áreas de interés nacional y expandiendo sus niveles de conflictividad a espacios en principio ajenos a la discusión política, como las cortes de justicia.

Una de las causas esenciales de estos conflictos se encuentra en el complejo y contradictorio entramado institucional y sus reformas. Por un lado, la ley de partidos no logró moderar o articular la fragmentación ideológica, étnica y regional de los grupos representados en el Congreso. Como consecuencia de ello, se aumentaron los costos de transacción política entre presidentes que buscaban promover políticas nacionales y legislaturas interesadas en representar intereses locales. Por otro lado, elementos del sistema electoral, como la doble vuelta para la elección de presidente, la adopción de una fórmula electoral personalizada para elegir a los legisladores, la imposibilidad de reelección legislativa y la adopción de un sistema personalizado de voto, atentaron de diversas formas a la creación de coaliciones estables.

Para doblegar a la oposición legislativa e imponer su agenda, a inicios de los ochenta el Ejecutivo hizo uso extensivo de sus capacidades para expedir decretos-leyes de urgencia económica y vetar total o parcialmente determinados proyectos de ley. Sin 
embargo, tal estrategia no sólo empeoró el antagonismo entre poderes del Estado sino que condujo al deterioro de la calidad de las políticas públicas. Frente a tal realidad, en la siguiente década se recurrió a la formación de coaliciones clandestinas, de agenda limitada, cortas en cuanto a duración, y orientadas a intercambiar votos por favores políticos (Mejía Acosta, 2009).

En el intento de terminar con este fenómeno, tanto las reformas de 1995 como la Constitución de 1998 buscaron fortalecer la capacidad institucional del presidente para impulsar su agenda de gobierno. La imposibilidad de que el Legislativo pueda destituir a los ministros como consecuencia del juicio político y la mayor discrecionalidad del Ejecutivo para la elaboración del presupuesto público, son algunas de las variaciones institucionales más relevantes. A la par, se eliminaron prácticas y mecanismos clientelares que se percibían como ilegales o corruptos por parte de la ciudadanía.

No obstante lo expuesto, la proporción de leyes aprobadas por el Congreso se mantuvo igualmente baja cuando se trató de proyectos ordinarios (36\%) y sensiblemente más alta en el caso de proyectos de urgencia económica $(66 \%)$, aunque con muy poca diferencia entre la época anterior y posterior a las reformas. De otro lado, los presidentes tuvieron que hacer un esfuerzo adicional para conseguir las mismas tasas de aprobación en el período post 1996. De hecho, las coaliciones de gobierno fueron más cortas (12 meses respecto a 19,2) y los presidentes iniciaron casi el doble de proyectos de urgencia económica por año $(5,9$ comparado con 3,2). La Tabla 1 describe la información antes expuesta.

Tabla 1: Duración de coaliciones y desempeño legislativo antes y después de las reformas constitucionales en Ecuador (1979-2006)

\begin{tabular}{lccccccc}
\hline Período & $\begin{array}{c}\text { Proporción } \\
\text { de proyectos } \\
\text { ordinarios (y } \\
\text { de urgencia) } \\
\text { iniciados por el } \\
\text { Ejecutivo }\end{array}$ & $\begin{array}{c}\text { Proyectos } \\
\text { ordinarios (y } \\
\text { de urgencia) } \\
\text { iniciados cada } \\
\text { año }\end{array}$ & $\begin{array}{c}\text { Promedio de } \\
\text { duración de la } \\
\text { coalición } \\
\text { (meses) }\end{array}$ & $\begin{array}{c}\text { Tasa de } \\
\text { renovación de } \\
\text { los gabinetes }{ }^{\text {a }}\end{array}$ & $\begin{array}{c}\text { Tasa de cambio } \\
\text { de partidos }^{b}\end{array}$ \\
\hline $1979-1995$ & 0,35 & $(0,68)$ & 9,3 & $(3,2)$ & 19,2 & 0,52 & 0,12 \\
$1996-2006$ & 0,38 & $(0,64)$ & 6,3 & $(5,9)$ & 12 & 0,58 & 0,09 \\
Total/Promedio & 0,36 & $(0,66)$ & 12,6 & $(12,3)$ & 15,6 & 0,54 & 0,11 \\
\hline
\end{tabular}

Fuente: Mejía Acosta y Polga Hecimovich, 2009.

Notas:

a) Datos de remoción de gabinetes disponibles hasta el año 2003.

b) Datos de cambio de partidos disponibles hasta el año 2002.

En resumen, los datos sugieren que las modificaciones institucionales no lograron fortalecer la posición del presidente y tampoco erradicar los mecanismos informales que facilitaban la cooperación entre Ejecutivo y Legislativo en el período anterior. Así, luego 
de los cambios normativos la volatilidad de los miembros del gabinete aumentó -para acomodar la formación de nuevas alianzas-, mientras que la proporción de diputados que se separaron de sus partidos -generalmente para votar junto con el gobierno- se mantuvo también casi sin cambios. Esto último, a pesar de la adopción de disposiciones para expulsar a legisladores que fueran desleales a sus bancadas. Finalmente, aun cuando se otorgaron mayores capacidades formales al Presidente, su habilidad para negociar y legitimar reformas con la participación de la oposición en el Congreso no fue exitosa.

\section{Independencia judicial}

Siendo la inestabilidad institucional y la ausencia de acuerdos mínimos dos de los rasgos esenciales del sistema político ecuatoriano, la justicia no podía estar ajena a dicha dinámica. Específicamente, las controversias entre Ejecutivo y Legislativo hallaron en la renovación anticipada e inconstitucional de la Corte Suprema (CS) y del Tribunal Constitucional (TC) un mecanismo alterno de salida a las crisis políticas. Así, en los treinta años de vida democrática del país la CS fue renovada en siete ocasiones (1984, 1985, 1990, 1997, 2004, 2005, 2009) mientras que el TC sufrió un proceso de inestabilidad institucional de similares características $(1997,2001,2003,2004,2005,2007)$. En ninguno de los casos anotados la salida de los jueces se dio atendiendo a los mecanismos de impeachment judicial establecidos formalmente.

Como corolario de lo anotado, los desempeños del Poder Judicial en el campo de la aplicación e interpretación de la ley fueron deficitarios. Además, restricciones presupuestarias, debilidades en la formación de jueces y personal de apoyo, y una legislación anquilosada en los procedimientos, derivaron en dos hechos puntuales. De un lado, el limitado acceso de la ciudadanía a la administración de justicia, con lo que la igualdad formal ante la ley presentó serias diferencias respecto a lo que ocurre cotidianamente. De otro, la presencia de pagos y otras prácticas ilegítimas como medios de dinamizar los procesos judiciales, con lo que se relativizó la imparcialidad de la justicia para resolver eficientemente la conflictividad social.

\section{Relaciones civiles-militares y estados de excepción}

Desde el retorno al régimen democrático las Fuerzas Armadas fueron reconocidas constitucionalmente como garantes del ordenamiento jurídico. ${ }^{6}$ Sin embargo, durante los episodios de inestabilidad institucional anotados, una característica recurrente ha sido la disonancia entre dicha declaración normativa y el comportamiento positivo de los actores. Así, en las caídas presidenciales registradas en la última década, las Fuerzas Armadas siempre fueron jugadores decisivos, aunque desempeñando roles diversos.

6 La ambigüedad de tal declaración (art. 183 de la anterior Constitución) ha sido corregida en la nueva Constitución. Así, desde el 28 de septiembre de 2008, la misión fundamental de las Fuerzas Armadas es la defensa de la soberanía y la integridad territorial (art. 158). 
Dicha variación en cuanto al papel asumido por los militares en tales crisis ha llevado a caracterizarlos como árbitros de última instancia o agentes de bloqueo político (Mejía Acosta y Polga Hecimovich, 2009).

En efecto, mientras en las salidas anticipadas de Bucaram (1997) y Gutiérrez (2005) las Fuerzas Armadas se limitaron a viabilizar dicha decisión, en el caso de Mahuad (2000) su planteamiento fue diferente, optando por participar de forma abierta en la arena política. Tal puntualización, a la par que deja entrever la diversidad de estrategias y recursos que los militares poseen en el Ecuador, daría cuenta de la multiplicidad de factores que explican el ya citado divorcio entre la prescripción y lo fáctico. En definitiva, todos los escenarios descritos conducen a relativizar la autonomía que poseen los gobiernos civiles respecto a las Fuerzas Armadas para la conducción de los asuntos públicos.

De hecho, las dinámicas que asume la declaratoria de "estado de emergencia" es una muestra palpable de la relación interdependiente que ha mantenido el Ejecutivo respecto a los militares. ${ }^{7}$ Dado que los diferentes gobiernos han recurrido a tal recurso para enfrentar paros y manifestaciones sociales consideradas peligrosas para su propia estabilidad (Dávalos, 2008: 149), la intensidad del apoyo brindado por las Fuerzas Armadas en dichos escenarios ha sido decisiva. En términos de teoría de juegos, el grado de participación de los militares durante los estados de emergencia tendría relación directa con las ofertas de pagos y con las amenazas de sanciones efectuadas desde el gobierno civil.

Sin embargo, el uso político otorgado al estado de emergencia no quiere decir que tal sea su naturaleza constitucional. Como recurso de excepción que es, su declaratoria está reservada para casos de inminente agresión externa, guerra internacional, grave conmoción interna o catástrofes naturales. No obstante, la laxitud de las causales anotadas -básicamente la relacionada a casos de grave conmoción interna- y la ausencia de una clara delimitación de los alcances de la medida han propiciado que por este medio se den violaciones a derechos y libertades fundamentales. De hecho, varias de las sentencias dictadas por la Corte Interamericana de Derechos Humanos en contra del Estado ecuatoriano han tenido como escenario estados de emergencia dictados sin justificación plena. Una de ellas, emblemática por la actualidad de la jurisprudencia que de allí se deriva (Dávalos, 2008: 150), es la dictada en el caso "Zambrano Vélez y otros vs. Ecuador". 8

$7 \quad$ La nueva Constitución es similar en cuanto a las causales que permiten al presidente decretar el ahora denominado estado de excepción. No obstante, sí existe un avance significativo en lo relacionado al otorgamiento de garantías ciudadanas frente al eventual abuso de tal recurso por parte del Jefe de Estado (art. 165).

8 El caso tiene como origen la declaratoria de emergencia dictada por el Presidente Durán Ballén (Decreto No 86 de 3 de septiembre de 1992) asumiendo que "actos de vandalismo" en las ciudades de Quito y Guayaquil daban lugar a una situación de grave conmoción interna a nivel nacional. Bajo dicho estado de excepción miembros de las Fuerzas Armadas violaron el domicilio y ejecutaron extrajudicialmente a varias personas. El hecho sucedió en una zona suburbana de la ciudad de Guayaquil (Dávalos, 2008: 150-151). 


\section{Protección de derechos civiles, políticos y libertad de prensa}

En la dimensión del respeto y protección a los derechos civiles Ecuador sigue presentando altibajos. Más allá de la referencia normativa, en cuyo ámbito tanto la Constitución de 1998 como la ahora vigente se describen como garantistas, existen episodios en los que las libertades de expresión, prensa y asociación quedan en entredicho. El enjuiciamiento penal propiciado por el actual Presidente a un medio de comunicación escrita, las reacciones del aparato estatal frente a la movilización de estudiantes opositores en las inmediaciones de la Universidad Católica de Guayaquil y otros eventos paradigmáticos, como la desaparición de los hermanos Restrepo durante la administración del ex presidente León Febres-Cordero, dan cuenta de lo dicho.

En el primer caso, bajo el título "Vandalismo oficial", el 9 de marzo de 2007 el diario "La Hora" de la ciudad de Quito señalaba que el Mandatario gobierna con "tumultos, piedras y palos". Esta expresión fue el fundamento de la denuncia que inmediatamente presentó el presidente Correa, sugiriendo que de esa forma se había perpetrado un hecho delictivo. A la par, en dicha acción judicial se solicitaba la privación de la libertad de director del citado medio de comunicación. ${ }^{9} \mathrm{Al}$ final, el presidente desistió de continuar impulsando la referida denuncia. En el otro episodio -suscitado en el año 2008-, mientras el Primer Mandatario dirigía uno de sus informes sabatinos desde la Universidad ya citada, un grupo de estudiantes exponía en las afueras su oposición al proyecto constitucional. Como consecuencia de ello, miembros de la Policía Nacional y de seguridad del presidente recurrieron a actos de violencia para aplacar dicha manifestación. Paradójicamente, la Fiscalía abrió una causa penal en la que acusaba a los estudiantes agredidos a la par que el presidente solicitaba la expulsión de los universitarios por atentar contra su vida. ${ }^{10}$

En relación a la tutela de derechos políticos, esta se encuentra condicionada a la distribución de poder entre las diversas fuerzas partidistas. En efecto, dado que el Tribunal Supremo Electoral (TSE) se conformaba -hasta el año 2008- a partir de cuotas asignadas entre los partidos políticos con mayor representación, la posibilidad de un trato asimétrico para las minorías estaba siempre presente. Por ello, aunque no se registran casos verificados de irregularidades o fraude en el conteo de votos, el abuso de recursos públicos con fines proselitistas ha sido una constante en la arena política nacional. ${ }^{11}$ Más allá de cuestiones relacionadas a la ausencia de una legislación coherente para el control del gasto electoral, en los rasgos del diseño institucional ya apuntados se hallaría una de las razones más influyentes para la valoración efectuada respecto a la equidad y protección de los derechos políticos en Ecuador.

Aunque estas irregularidades se dan en las distintas instancias de gobierno, quien suele sacar mayor provecho electoral del uso de recursos públicos es el representante del Ejecutivo. El caso de la campaña a favor del referéndum propiciado por el actual presidente es un caso paradigmático de lo expuesto; sin embargo, las prácticas anotadas no han sido extrañas al resto de agrupaciones y actores que han desempeñado la primera magistratura del país. 


\section{c. Democracia social y económica}

Ecuador es un país de ingresos medio-bajos y altamente dependiente de sus exportaciones petroleras. De hecho, mientras en el período 1979 - 2005 el petróleo representó el 37\% de los ingresos del gobierno central y el $48 \%$ de las exportaciones promedio, durante el reciente boom de exportaciones petrolíferas (2005 - 2008) este rubro subió a 49\% de los ingresos gubernamentales y al 60\% de las exportaciones promedio (Albornoz y Mejía Acosta, 2009). Como consecuencia de ello, la distribución de las rentas petroleras ha sido un tema de intenso conflicto político, pues existe la expectativa de que una mayor riqueza tendría impacto positivo sobre las condiciones económicas y sociales de la ciudadanía. Sin embargo, aunque el precio del petróleo afecta directamente los ingresos del gobierno, el gasto, el balance fiscal y el crecimiento de la economía, no se registra evidencia de que tal riqueza contribuya a mejorar los indicadores socioeconómicos. En sentido contrario, una reducción de los ingresos petroleros por interrupciones en la producción (como en 1987) o por caídas en los precios internacionales (como en 1999 y 2008), sí podría aumentar la pobreza e inequidades sociales.

En consonancia con lo señalado, no existen pruebas consistentes que permitan afirmar que un contexto de incertidumbre económica está asociado con una mayor inestabilidad política. De hecho, sólo en una de las tres ocasiones en que los presidentes fueron derrocados -durante la caída de Mahuad en enero de 2000- se puede decir que la crisis económica fue un factor de inestabilidad. En ese plano, durante los últimos años Ecuador muestra una interesante paradoja, pues la recuperación de los indicadores económicos tras la crisis de 1999 ocurre de manera simultánea con la erosión de la democracia.

En el campo social, durante la administración del presidente Correa se ha constatado una reducción de la tasa de desempleo -en áreas urbanas- del 8,5\% en 2005 a 8,1\% en el 2006; y, del 7,4\% en 2007 a 6,9\% en 2008 (CEPAL, Anuario Estadístico de América Latina y El Caribe 2008). ${ }^{12}$ Además, el índice de Gini presenta una mejora, pues en el año 2007 se situaba en 52,0 mientras que en el 2008 se colocó en 48,0 (CEPAL, Panorama Social 2009). Por otro lado, a pesar de que el promedio de participación del sector social en el Producto Interno Bruto (PIB) sigue siendo bajo (4,71\%) en comparación con América Latina -cuyo promedio ponderado es de 15,8\% (CEPAL, Panorama Social 2007)-, a lo largo de los últimos años se ha registrado un importante incremento en este rubro. Como se observa en la Figura No 1, la inversión social en relación al PIB durante los años 2007 y 2008 es la más alta desde el año 2000. Dicha cifra sugiere, por tanto, un mayor compromiso del actual gobierno con el financiamiento y satisfacción de necesidades básicas de la ciudadanía.

12 En las cifras entregadas se incluye una valoración del desempleo oculto. En el año 2005 las cifras corresponden a una medición realizada en las ciudades de Quito, Guayaquil y Cuenca. Finalmente, para el año 2008 el dato se basa en una estimación basada en el promedio de enero a septiembre. 
Figura 1: Ejecución de la inversión social como porcentaje del PIB (2000-2008)

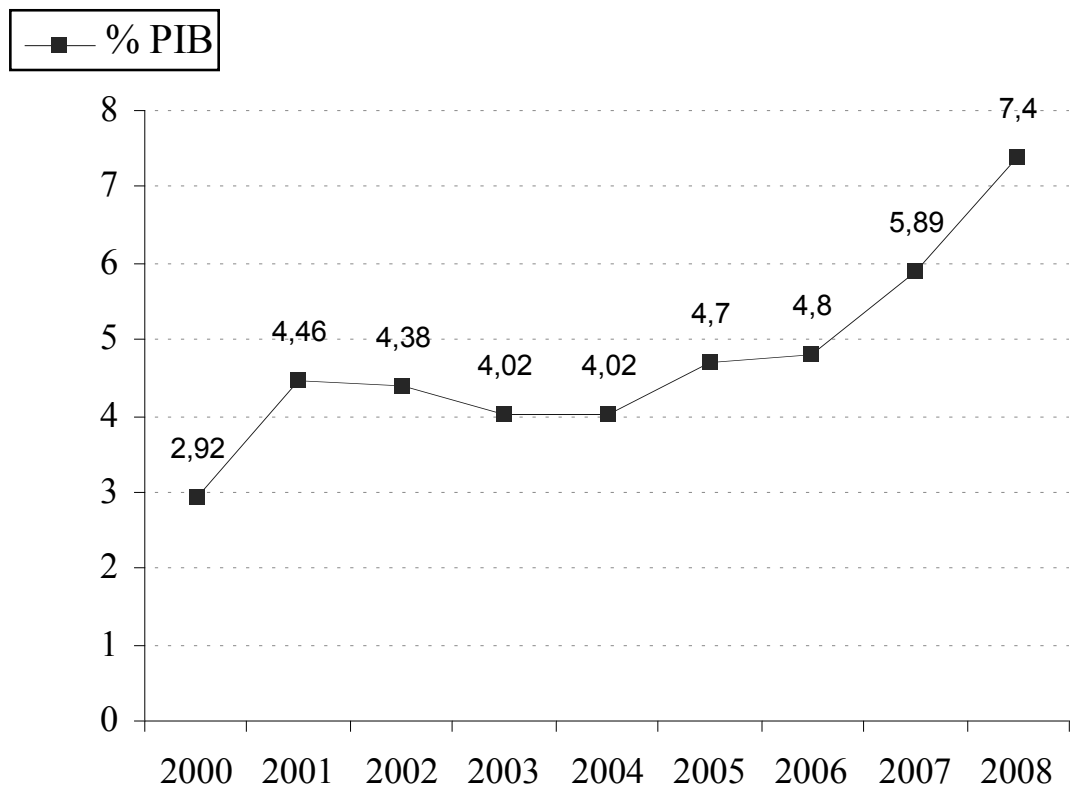

Fuente: Ministerio de Finanzas - Ministerio de Coordinación de Desarrollo Social. Elaboración: propia.

Finalmente, la propuesta de reformar el sistema educativo nacional -en el que se incluye a la educación superior-, colonizado por más de treinta años por el maoísta partido Movimiento Popular Democrático (MPD), evidencia un interés puntual del presidente Correa por atender a un sector al que tradicionalmente se había otorgado poca o ninguna atención. Lo dicho, sumado a la descripción del párrafo anterior permite concluir que, a diferencia de gobiernos anteriores, la administración del presidente Correa ha puesto un mayor énfasis en la dimensión social de la democracia.

\section{ASCENSO Y CONSOLIDACIÓN DE LA “REVOLUCIÓN CIUDADANA": RUPTURAS Y CONTINUIDADES}

La elección de Rafael Correa, el 26 de noviembre de 2006, marcó un punto de inflexión al gradual proceso de deslegitimación de los actores y agrupaciones partidistas tradicionales. Su triunfo electoral se explica por su carisma político y su capacidad para movilizar votantes apáticos; aunque factores de tipo estructural relacionados con el pobre funcionamiento del sistema político ecuatoriano también fueron influyentes. Con dicho preámbulo, a continuación se discuten brevemente algunas de las variables mencionadas. 


\section{a. El ascenso de la "revolución ciudadana"}

No es la primera vez que una estrategia de ataque a la denominada partidocracia trae grandes ganancias electorales. De hecho, el discurso antisistema ha estado presente en la estructura de la actividad electoral desde los años cincuenta, siendo el ex presidente Velasco Ibarra su principal figura. Al respecto, a continuación se ofrecen algunos referentes empíricos. En la primera vuelta presidencial del año 1996, los candidatos ubicados en el segundo y tercer lugar -Abdalá Bucaram $(26,2 \%)^{13}$ y Fredy Ehlers $(20,6 \%),{ }^{14}$ respectivamente- articularon sus campañas alrededor de la negación de actores y estructuras partidistas tradicionales (Pachano, 2008). ${ }^{15}$ De la misma forma, en las elecciones de 1998, Álvaro Noboa, otro actor sin antecedentes políticos, no sólo alcanzó el segundo lugar sino que la diferencia con el candidato ganador fue de apenas tres puntos porcentuales. ${ }^{16}$ Finalmente, en 2002, Lucio Gutiérrez ganó la elección presidencial con un discurso también antisistémico en el que se anteponía como referente propagandístico su participación en el golpe de Estado contra el ex presidente Mahuad.

Dada la similitud de patrones de comportamiento hallados en los distintos eventos anotados y los vínculos causales que enlazan a unos respecto de otros, el ascenso de Rafael Correa constituiría el corolario de un proceso de mayor alcance. Así, el surgimiento de la "revolución ciudadana" refleja el colapso tanto del modelo político propuesto por la Constitución de 1978 como de las fallidas reformas establecidas en la de 1998. En ese plano, otra de las lógicas recurrentes en la política nacional está en la idea de que es necesario variar el diseño constitucional tan pronto como se presenten modificaciones importantes en la distribución del poder.

Bajo dicha lógica, la promesa de liderar una profunda reforma política que termine en una nueva Asamblea Constituyente tampoco es un atributo especial del presidente Correa. De allí que la Carta de 2008 sea solamente el más reciente eslabón en una cadena de veinte constituciones anteriores, todas adoptadas bajo similares pretensiones de renovación del sistema político. De hecho, tanto en el interinazgo de Fabián Alarcón como en la presidencia de Gustavo Noboa, Lucio Gutiérrez y Alfredo Palacio, la idea de sustituir o al menos reformar la Constitución fue una propuesta recurrente. Sin embargo, lo que marca la diferencia entre el actual gobierno y sus predecesores radica, precisamente, en su capacidad política para obtener exitosamente tal variación institucional. En dicho

13 A pesar de su larga trayectoria política, Bucaram puede ser considerado como un candidato antisistema (Pachano, 2008: 3).

14 Ehlers no registraba una vida política activa de forma previa al proceso electoral mencionado. Sus funciones básicas se desempeñaron siempre alrededor del periodismo y los medios de comunicación.

15 En la segunda vuelta electoral, Bucaram superó al candidato del Partido Social Cristiano (PSC) Jaime Nebot. Nuevamente, el discurso de negación a un actor político tradicional y a su estructura partidista fueron elementos decisivos para el acceso al poder de Bucaram.

16 Álvaro Noboa obtuvo el 26,6\% de la votación en la primera vuelta electoral. En la segunda su votación alcanzó el 48,3\% de los votos válidos (Pachano, 2008: 3). Al igual que en los comicios presidenciales de 1996, en esta ocasión se volvieron a enfrentar un representante de la "partidocracia" como era Jamil Mahuad -y antes Jaime Nebot-, frente a candidatos considerados outsiders. 
rasgo de la "revolución ciudadana" se hallaría una explicación adicional de su auge y popularidad.

\section{b. Auge y sedimentación del fenómeno Correa}

Lo contradictorio del proceso político encarnado por el presidente Correa radica en que actores y prácticas políticas del pasado y que constantemente son denostadas por el Jefe de Estado son las que, paradójicamente, viabilizaron la Constitución vigente desde finales del 2008 (Basabe Serrano, 2009a). Así, las dinámicas de intercambio, favores y pagos de diversa índole que eran comunes en épocas anteriores hallaron su correlato en diferentes episodios clave del período de la "revolución ciudadana". De ellos, el conjunto de acuerdos entre Ejecutivo, Legislativo y Tribunal Supremo Electoral (TSE), y que dio lugar al surgimiento de los diputados de los manteles y la posterior instalación de la Asamblea de Montecristi es uno de los más trascendentes.

En efecto, luego de tensiones entre Ejecutivo y Legislativo por la negativa de este último a aprobar la convocatoria a una consulta popular que viabilice el proceso constituyente, el TSE decidió destituir de sus funciones a los cincuenta y siete diputados que firmaron dicha resolución. El argumento esgrimido era que, por hallarse el país en medio de un proceso electoral, la actuación de los legisladores alteraba dicha dinámica. Como consecuencia de ello, y a pesar de que el Tribunal Constitucional había declarado que la decisión del TSE era violatoria a la Carta Política, el Congreso Nacional dio paso a que los diputados suplentes de los cesados asumieran las curules.

A los pocos días de que los mencionados legisladores se hallaban en funciones, algunos medios de comunicación captaron imágenes de una reunión -en las afueras de la ciudad de Quito- en la que miembros del gobierno nacional llegaban a un acuerdo de cooperación con tales actores. Al detectar la presencia de los periodistas, varios de estos diputados salieron del lugar de encuentro cubriéndose el rostro con manteles, surgiendo de allí el apelativo mencionado en el primer párrafo de este numeral. Así, con una mayoría consolidada a partir de los acuerdos subterráneos indicados, la consulta popular y la posterior convocatoria a Asamblea Constituyente no tuvieron oposición alguna en la legislatura. ${ }^{17}$

Por otro lado, tanto en la integración del gabinete ministerial como en otros espacios clave es notoria la presencia de aquellos políticos que, por sus antecedentes, son parte del blanco de ataque del presidente Correa. Nombres como los de Jorge Marún (ex diputado, prefecto y ministro del presidente Bucaram), Carlos Vallejo (ex ministro y diputado por la UDC y luego por el PRIAN), Nicolás Issa Obando ( ex diputado por la ID y luego dirigente del PRE), Alfredo Vera (ex ministro del presidente Borja y dirigente

17 Luego de más de dos años de los sucesos relatados, recientes declaraciones del hermano del presidente Correa volvieron a colocar en la discusión política nacional este hecho. Al respecto, se puede recurrir a la nota de prensa "Revelaciones de F. Correa reviven pagos a diputados de los manteles", publicada en el diario $E l$ Universo, de fecha 23 de junio de 2009. 
de la ID), Raúl Vallejo (ex ministro del presidente Palacio y afiliado hasta hace poco a la ID), Ramiro González (ex prefecto provincial por la ID), Antonio Gagliardo (ministro del presidente Borja y ex diputado por la ID) o Alexis Mera (ex asesor jurídico de los dirigentes socialcristianos Jaime Nebot y León Febres Cordero), constituyen evidencia empírica de lo anotado.

Finalmente, la incapacidad de los sectores de oposición para articular una propuesta alternativa y la identificación del "enemigo" en las políticas norteamericanas y los medios de comunicación, han sido suficientes para que la administración del presidente Correa obtenga resultados positivos en las últimas cuatro elecciones registradas en Ecuador. Respecto a la relación del Jefe de Estado con los periodistas, el último informe para el Ecuador de la Sociedad Interamericana de Prensa (SIP) señala que: "El gobierno continúa amenazando e insultando sistemáticamente a la prensa y a los periodistas. En su programa de radio y televisión de los sábados, el Primer Mandatario constantemente describe un escenario según el cual el causante de casi todos los males del país es el periodismo". ${ }^{18}$

\section{LOS DESAFÍOS DE LA NUEVA CONSTITUCIÓN}

Puesto que resulta prematuro hacer un análisis amplio de los efectos de la nueva Constitución, hemos seleccionado tres dimensiones que, siendo críticas para el funcionamiento de la democracia, permiten reflexionar sobre los posibles resultados que arrojará el naciente diseño institucional. En primer lugar, consideramos las dinámicas que asumirá la relación entre aparato estatal y ciudadanía y sus implicaciones sobre la participación democrática. Luego se analiza el conjunto de incentivos selectivos otorgados a Ejecutivo y Legislativo y sus repercusiones en términos de balance de poderes. Algunas reflexiones sobre el Estado de Derecho y su viabilidad cierran el presente numeral.

\section{a. Participación ciudadana}

La iniciativa legislativa (art. 103), la consulta popular (art. 104) y la revocatoria del mandato (art. 105) son las formas básicas de democracia directa que constan en la nueva Constitución. ${ }^{19}$ A pesar de su aparente novedad, estos mecanismos ya estuvieron presentes en la legislación ecuatoriana en varios momentos. Así, la consulta popular fue establecida en la Constitución de 1967 (art. 72), se la retomó en la de 1979 (art. 35) y se la mantuvo en la de 1998 (arts. 103-108). La iniciativa legislativa se incorporó por primera vez en la Constitución de 1979 (art. 65) y se la ratificó en la de 1998 (art. 146). Finalmente,

18 El informe ampliado se encuentra en la página web oficial de dicha organización: http://www.sipiapa.org

19 Un mecanismo adicional es el presupuesto participativo; sin embargo, constituye una forma diferente de intervención, dado su carácter corporativo. 
la revocatoria del mandato es la más reciente, pues consta a partir de la Carta Política de 1998 (arts. 109-113). ${ }^{20}$

Sin embargo, lo que sí llama la atención es que la sección en la que la nueva Constitución incluye a la iniciativa legislativa, la consulta popular y la revocatoria de mandato, precede a la de organizaciones políticas -sección quinta- y a la de representación política -sección sexta-. Si se considera dicho orden expositivo es posible asumir que se está colocando a la democracia representativa después de las formas de democracia directa. Esto significa, entre otras cosas, que antes de establecer el derecho de las personas a conformar las instancias del poder político, esto es, a otorgar un mandato, se consigna el derecho a revocarlo.

Por otro lado, y más allá de cambios en cuanto a los requisitos para viabilizar los mecanismos de democracia directa, las variaciones más profundas se encuentran en las disposiciones referidas a la participación popular y a la construcción del poder ciudadano. En ese plano, la Constitución propone una concepción de democracia en la que se socava el principio básico de la igualdad política de la ciudadanía. Específicamente, planteamos que la nueva arquitectura constitucional propone modalidades corporativas de participación que son opuestas a la representación popular expresada en la igualdad del voto.

Así, el art. 100 plantea que: “En todos los niveles de gobierno se conformarán instancias de participación integradas por autoridades electas, representantes del régimen dependiente y representantes de la sociedad". Por consiguiente, dicha disposición coloca a los mandatarios de la ciudadanía, que han recibido un encargo por la vía electoral, en el mismo nivel que: (i) las personas que tienen deseo de participar pero que no expresan la voluntad popular; y, (ii) que los integrantes del régimen dependiente, que ejercen una delegación del Ejecutivo. Tal rasgo institucional conducirá, por tanto, a erosionar la voluntad de los electores, sometiéndola a las decisiones de pequeños grupos.

Dicha característica se torna empíricamente observable en la conformación de la denominada Función de Transparencia y Control Social (capítulo quinto del título IV), dentro de la que el Consejo de Participación Ciudadana y Control Social (CPCCS) es la instancia más decisiva. En efecto, el CPCCS, cuyos integrantes no son elegidos a través de las urnas sino vía concurso de merecimientos, tiene la potestad de designar al Procurador General, al Defensor Público, al Fiscal General, a los miembros del Consejo Nacional Electoral, a los del Tribunal Contencioso Electoral y a los del Consejo de la Judicatura (art. 208, numerales 11-12). Así, este organismo asume las funciones de nominación y designación que, en cualquier régimen democrático, son asignadas al órgano legislativo -como había sucedido en Ecuador hasta el año 2008-. Como consecuencia de lo dicho, las atribuciones de un organismo de elección universal, y que por ello ostenta la representación de la voluntad ciudadana, han sido trasladadas a siete personas, carentes de mandato popular.

20 A pesar de la existencia de los mecanismos de democracia directa anotados, la ciudadanía nunca recurrió a ellos. Los altos costos de transacción o la ausencia de una conciencia clara de lo que significa poseer derechos constitucionales pueden ser algunas de las razones que explican este fenómeno. 


\section{b. El balance de poderes}

La adopción de reformas constitucionales en 2008 se dio en un contexto distinto al que existió durante los períodos 1977-78 y 1997-98. Por un lado, el proceso fue auspiciado por el gobierno en funciones; por otro, el partido oficialista se benefició de una representación mayoritaria en la Asamblea Constituyente. Tal combinación de factores es decisiva pues, como lo muestra la evidencia comparada para América Latina, esta asimetría de poder tiende a reducir los incentivos que tiene la oposición para consolidar el nuevo pacto constitucional (Corrales, 2008). Por ello, lejos de crear condiciones de concertación que fortalezcan el proceso democrático, el (des)balance de poderes hallado en la nueva Constitución contendría las simientes de mayor inestabilidad política a futuro.

En el campo de las relaciones entre Ejecutivo y Legislativo, la nueva Constitución refuerza y aumenta el predominio del Presidente sobre los otros poderes del Estado. Formalmente, se le concede la capacidad exclusiva para influir sobre la planificación económica (art. 279), elaborar el Presupuesto General del Estado (arts. 291-3), establecer el régimen tributario (art. 299), determinar la política monetaria, cambiaria y crediticia (art. 300), decidir sobre el control de los sectores estratégicos (arts. 311, 314, 315); y, regular las transferencias a los gobiernos subnacionales (art. 157). Estas nuevas capacidades vienen a reforzar las ya existentes para legislar por decreto, convocar consultas populares y vetar legislación.

$\mathrm{Al}$ respecto, la literatura sobre presidencialismo ha señalado que otorgar amplios poderes al Ejecutivo busca compensar la ausencia de respaldo político al gobierno desde el Congreso (Mainwaring y Shugart, 1997; Morgenstern y Nacif, 2002). Una breve evaluación de los sistemas presidenciales en América Latina confirma la existencia de un intercambio entre poderes presidenciales fuertes con bancadas legislativas débiles -como fue el caso de Brasil con los presidentes Cardoso y Lula durante los años 90- o la situación inversa, de presidentes con el apoyo de partidos fuertes para compensar la debilidad de sus poderes constitucionales -como en el mal llamado "hiperpresidencialismo" de México durante el predominio del PRI-. En el caso ecuatoriano, si a las sucesivas reformas constitucionales orientadas a fortalecer el poder presidencial se suma el estatus cuasimayoritario del partido oficialista en la Asamblea Nacional, es posible catalogar a la Constitución de este país -junto a la de Venezuela- como una de las más presidencialistas de la región. La Tabla 2 expresa las trayectorias constitucionales de varios países latinoamericanos.

La tendencia a fortalecer el poder del Presidente a costa de la legislatura puede observarse también en el proceso de formación de políticas públicas. Las capacidades de iniciar legislación urgente en materia económica (art. 142), vetar iniciativas de ley, e incluso proponer un texto alterno que solo podría ser modificado con el voto de una mayoría legislativa calificada (2/3 de los votos, art. 140) dan cuenta de tal afirmación. Por otro lado, en el campo presupuestario el Presidente tiene la exclusividad para iniciar dicho proceso, presentar proyectos que creen, modifiquen o supriman impuestos, aumenten el gasto público o modifiquen la división político administrativa del país (art. 137). Lo dicho, sumado a la creación de una Cuenta Única del Tesoro Nacional (art. 297) confirma la ampliación del poder discrecional del Ejecutivo sobre el Legislativo. 
Tabla 2: Presidencialismos y reforma constitucional en América Latina

\begin{tabular}{ccc}
\hline $\begin{array}{c}\text { Poderes constitucionales } \\
\text { vs. Poderes partidistas }\end{array}$ & Minoría legislativa & Mayoría legislativa \\
\hline $\begin{array}{c}\text { Débil influencia legislativa } \\
\text { del presidente }\end{array}$ & Brasil 46, Chile 25, & $\begin{array}{c}\text { El Salvador, Uruguay, } \\
\text { Costa Rica, Paraguay 91, } \\
\text { Venezuela <99, México. }\end{array}$ \\
\hline $\begin{array}{c}\text { Fuerte influencia legislativa } \\
\text { del presidente }\end{array}$ & Ecuador 1979 & Argentina 1994; \\
& Chile 89, Colombia 68, & Venezuela 1999, \\
& Brasil 88, Colombia 91, & Ecuador 2008 \\
\hline
\end{tabular}

Fuente: Mainwaring y Shugart, 1997.

\section{c. Independencia judicial y Estado de Derecho}

La nueva Carta Política marca rutas diferentes para las nacientes Cortes Nacional y Constitucional. Mientras la primera pierde en autonomía y estabilidad laboral (al eliminarse los períodos indefinidos), la otra se erige como una corporación de juzgadores de la política que, sin embargo, no rinde cuentas de ningún tipo (al eliminarse el juicio ante la legislatura). Así, lejos de fortalecer a la administración de justicia, el diseño constitucional ha contribuido a debilitarla. Más aún, la nueva Carta Política ha iniciado su declaración de principios señalando que Ecuador es un estado constitucional de derechos, en plural (art. 1), lo que constituye una afirmación incomprensible y sin justificación jurídica alguna. Bajo las premisas anotadas, a continuación analizamos las dos instituciones más importantes de la justicia ecuatoriana, enfatizando en la incidencia que la reforma podría generar sobre el comportamiento de los jueces y, en definitiva, sobre los rendimientos de la democracia.

A fin de evitar la injerencia de actores políticos en la designación de los integrantes de la Corte Suprema, la Constitución de 1998 recurrió al mecanismo de cooptación. Con dicha fórmula se buscaba que los propios jueces seleccionasen a sus colegas cuando se presentara una vacante, conminándolos al mismo tiempo a iniciar procesos de autodepuración si las circunstancias lo ameritaban. La lógica de razonamiento era que, siendo una función tan técnica y especializada la de administrar justicia a ese nivel, quienes mejor podrían escoger a las personas idóneas para el efecto eran, precisamente, aquellos que conocían de la materia. Con las debilidades que el diseño institucional mencionado podía ocasionar, hasta el 2008 fue la salida más viable al fantasma de la politización de la justicia que había rondado la vida democrática Ecuador desde 1979.

No obstante, la nueva Constitución varió el mecanismo citado, encargando al Consejo de la Judicatura (CJ) la selección de los jueces ahora denominados nacionales. Así, un organismo conformado por nueve personas, de las que la tercera parte no tendrán formación como abogados (art. 180), será el que designe a la más alta instancia de justicia ordinaria del país. Como consecuencia de ello, al menos dos efectos se vislumbran sobre la Corte Nacional. De un lado, la pérdida de autonomía en cuanto a su funcionamiento; 
y, de otro, la posibilidad de que sean las organizaciones sociales representadas en los integrantes del CJ las que presionen por conseguir espacios de poder al interior del mencionado órgano de justicia.

Desde otra perspectiva, y siguiendo la idea republicana de que la ausencia de períodos fijos es el mecanismo más idóneo para mejorar el desempeño de los jueces, la Constitución de 1998 establecía tal declaración respecto a la Corte Suprema. Al respecto, el nuevo diseño ha limitado el tiempo de funciones de sus miembros a 9 años, lo que sumado a la imposibilidad de la reelección (art. 182) genera dificultades para la formación de criterios jurídicos unificados y estables en el tiempo. Luego, la interacción de períodos fijos y designación por parte de actores ajenos a la Corte erosiona la autonomía y estabilidad que se podían construir al interior de tal corporación. Aunque existían aspectos del funcionamiento del Poder Judicial que debían ser enmendados, los mecanismos de selección y los plazos no se contaban entre ellos. ${ }^{21}$

En cuanto a la Corte Constitucional, el nuevo esquema otorga a este órgano una serie de facultades que van más allá del control y defensa de las garantías y derechos ciudadanos. En efecto, cuando el Presidente intente disolver la Asamblea Nacional o cuando ésta propicie la destitución de aquél, la intervención de los jueces de dicho órgano es decisiva (arts. 130 y 148). Por otro lado, en aquellos casos en los que se desee revisar una sentencia judicial ejecutoriada, esta Corte estará facultada para ello (art. 437). En principio, el papel estelar otorgado al citado órgano de justicia es plausible y, además, se halla ya legislado en otros países. Desde esa perspectiva, la crítica no es a la amplitud de facultades concedidas a la Corte Constitucional sino a la ausencia de mecanismos de control y rendición de cuentas.

Dentro de un régimen democrático, cuando a una institución se le otorga mayor poder político el medio más eficaz para morigerar posibles excesos es que otra institución, provista de capacidades similares, pueda cuestionarla y controlarla. Esa es la esencia de la fórmula institucional de los pesos y contrapesos. En el caso concreto, si la Corte Constitucional se presenta como un actor con capacidad de incidencia directa sobre la vida política del país, lo mínimo que se podía esperar es que sus miembros estén sometidos a algún mecanismo de rendición de cuentas. Para el efecto, la Constitución de 1998 señalaba que los Vocales del Tribunal Constitucional -antecedente inmediato de la Corte citada- eran susceptibles de enjuiciamiento político por parte del Congreso Nacional. Si bien a primera vista ese mecanismo podría ser comprendido como una limitante a la independencia de los jueces constitucionales, en realidad actuó como un mecanismo de balance y de control tácito.

Así, a pesar de que nunca se destituyó por esta vía a un juez constitucional, la posibilidad de hacerlo jugó un papel catalizador en la actividad de ese órgano de justicia. De hecho, trabajos realizados sobre el comportamiento de estos juzgadores han evidenciado que sus actitudes políticas primaron en la resolución de los casos, dejando sin sustento la

21 Dinamizar el recurso de casación y tornar más ágil el despacho de las causas eran algunos de los clamores ciudadanos más importantes. Sin embargo, para tales cuestiones la reducción de 31 a 21 jueces supremos es otra de las enmiendas que generará un efecto contrario. 
idea popularmente difundida de que tales actores respondían a orientaciones ideológicas diversas (Basabe Serrano, 2008; 2009). En todo caso, más allá de la conveniencia o no del citado mecanismo de control, el hecho cierto es que la nueva Constitución no establece institución alguna ante la que los integrantes de la Corte Constitucional rindan cuentas. Solamente cuando tales actores cometieren un hecho delictivo se abre la posibilidad del enjuiciamiento y, aún en este caso, las características del procedimiento lejos de dejar sin sustento el argumento expuesto terminan fortaleciéndolo aún más.

En efecto, cuando un juez de la Corte Constitucional fuere declarado responsable por la comisión de un delito, dicha sentencia -que deberá contar con el voto de las dos terceras partes de los integrantes de la Corte Nacional- no implica necesariamente la destitución del cargo. Paradójicamente, para la remoción del juez sentenciado penalmente se requerirá que 6 de los 9 integrantes de la propia Corte Constitucional decidan la destitución de su colega (art. 431). De allí que en un escenario no imposible de verificarse, un juez condenado por un delito común podría al mismo tiempo mantenerse como miembro de la Corte Constitucional.

En resumen, la interacción entre las amplias facultades para regular la vida política del país y la reducción de los mecanismos de control hacen de la Corte Constitucional un órgano codiciado. Dicha ambición, natural entre abogados y juristas, podría resultar peligrosa cuando constituye un objetivo a satisfacer por parte de las agrupaciones partidistas. En ese plano, el divorcio entre la amplia argumentación jurídica desarrollada para crear la nueva Corte Constitucional y la miopía respecto a los efectos políticos que de allí se podría derivar, constituye el rasgo más prominente de dicho órgano de justicia. ${ }^{22}$

\section{CONCLUSIONES}

Luego del análisis de los rendimientos de la democracia ecuatoriana es posible identificar tres momentos políticos clave cuyos puntos de ruptura se encuentran en la promulgación de las constituciones de 1979, 1998 y 2008. El primero se inicia con el retorno a la democracia y concluye con la salida anticipada del presidente Bucaram. Es una etapa de emergencia de nuevos liderazgos políticos y al mismo tiempo de conflictos entre actores -los electos y los no electos- e intereses regionales excluyentes. A esto se suma la ampliación de la participación electoral, la que trae consigo el surgimiento de demandas específicas de sectores indígenas y de otras minorías. En términos redistributivos, se da una intensa pugna por las principales fuentes de poder político y económico.

Con la promulgación de la Constitución de 1998 se inaugura la segunda etapa democrática del país. La crisis financiera de 1999, la caída de los precios del petróleo y un tibio proceso de reformas institucionales son los principales rasgos de esta fase. En lo institucional, 
los poderes del Ejecutivo se incrementan, con la consiguiente merma en la capacidad de maniobra del Legislativo. Como consecuencia de ello, el desprestigio del Congreso crece y sus funciones se restringen a lo fiscalizador. Por otro lado, la ausencia de partidos de ámbito nacional reorienta a los líderes hacia la política local, sentando las bases para el surgimiento de opciones antisistémicas. Irónicamente, la recuperación de la economía ecuatoriana entre los años 2000 y 2006 va acompañada de una progresiva des-estructuración del sistema político, cuya consecuencia más clara se encuentra en el surgimiento y consolidación del presidente Correa.

En efecto, el año 2006 marca el inicio de la tercera etapa de la vida política de Ecuador aunque su consolidación se encuentra en la promulgación de la Constitución de Montecristi, en 2008. En lo político, el presidente Correa ganó secuenciales elecciones fundamentando su discurso en la crítica a los partidos tradicionales y condenando las prácticas corruptas y antijurídicas del antiguo orden. No obstante, no ha reparado en violentar la legalidad, incluso de su propia Constitución, ni ha puesto reparos a gobernar con fuerzas políticas que fueron protagonistas de la inestabilidad política del período anterior (MPD, ID, PRE, entre otros). En lo económico, aunque el gobierno tomó como blanco de ataque a las políticas macro de las administraciones previas, buena parte de su éxito electoral se debe a la estabilidad proveniente de la dolarización, al control de la inflación y a la reducción de la pobreza; todas atribuibles a gobiernos anteriores.

En síntesis, la democracia ecuatoriana ha transitado a lo largo del período analizado de un extremo de bloqueo institucional a otro de personalismo unívoco. En dicho proceso, y a pesar de la promulgación de tres cartas constitucionales, el pluralismo político, la elaboración de políticas públicas estables y el equilibrio en la relación entre poderes del Estado fueron -y siguen siendo- residuales. Al final, la sedimentación de las instituciones políticas, el respeto al Imperio de la Ley y la construcción de una ciudadanía plena -en términos de derechos y obligaciones- aún son cuestiones por construir. Sin ellas, los rendimientos del régimen democrático continuarán presentando los desniveles que este trabajo ha evidenciado.

\section{REFERENCIAS}

Albornoz, Vicente y Andrés Mejía Acosta. 2009. Budget Coalitions and Municipal Spending in Ecuador. IDS Working Paper. Brighton: IDS (en prensa).

Basabe Serrano, Santiago. 2008. "Preferencias ideológicas y políticas judiciales: un modelo actitudinal sobre el voto en el Tribunal Constitucional del Ecuador". América Latina Hoy 49: 157-177.

Basabe Serrano, Santiago. 2009. “Jueces sin toga: Políticas judiciales, preferencias ideológicas y proceso de toma de decisiones en el Tribunal Constitucional del Ecuador (1999-2007)", Disertación Doctoral. Escuela de Política y Gobierno - Universidad Nacional de San Martín (Buenos Aires, Argentina).

Basabe Serrano, Santiago. 2009a. "Ecuador: reforma constitucional, nuevos actores políticos y viejas prácticas partidistas". Revista de Ciencia Política 29 (2): 381-406.

CEDATOS/Gallup Internacional. (en línea) www.cedatos.com.ec (Consulta : varios días).

Comisión Económica para América Latina y el Caribe. (en línea). Panorama Social 2007.http://www. eclac.org/cgibin/getProd.asp?xml=/publicaciones/xml/5/30305/P30305.xml\&xsl=/dds/tpl/p9f. xsl\&base=/tpl/top-bottom.xsl (Consulta: 09-09-09). 
Comisión Económica para América Latina y El Caribe. (en línea) Anuario Estadístico para América Latina y El Caribe 2008. http://websie.eclac.cl/anuario_estadistico/anuario_2008/datos/1.2.17. xls (Consulta: 07-09-09).

Conaghan, Catherine. 1995. "Políticos versus partidos: discordia y desunión en el Sistema de partidos ecuatoriano". En La construcción de instituciones democráticas. El sistema de partidos en América Latina. Mainwaring, Scott y Timothy Scully (edits.). Santiago: CIEPLAN.

Constitución del Ecuador, R.O. No 1 de 10 de agosto de 1998. (en línea) http://www.ecuanex.net.ec/ constitucion (Consulta: varios días)).

Constitución del Ecuador, R.O. N 401 de 12 de agosto de 2008. (en línea) http:/ / www.asambleaconstituyente. gov.ec/documentos/constitucion_de_bolsillo.pdf (Consulta: varios días).

Corrales, Javier. 2008. "Latin America's Neocaudillismo: Ex presidents and Newcomers Running for President...and Winning". Latin American Politics and Society 50: 1-35.

Dávalos Muirragui, María Daniela. 2008. “Estados de excepción: mal necesario o herramienta mal utilizada? Una Mirada desde el constitucionalismo contemporáneo". En Neoconstitucionalismo y sociedad. Ávila Santamaría, Ramiro (edit). Quito: Ministerio de Justicia y Derechos Humanos. Pp. 123-162.

Diario El Universo. (en línea) www.eluniverso.com (Consulta: varios días).

Instituto Ecuatoriano de Estadísticas y Censos (en línea). Censo de Población y Vivienda 2001. http:/ /157.100.121.12/cgibin/RpWebEngine.exe/PortalAction?\&MODE=MAIN\&BA

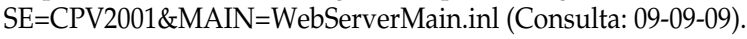

Ley de elecciones, R.O. N 20 de 17 de marzo de 2000.

Ley Orgánica de Control de Gasto Electoral y de la Propaganda Electoral, R.O. Nº 241 de 31 de marzo de 2006.

Mainwaring, Scott y Matthew Shugart. 1997. Presidentialism and Democracy in Latin America. Cambridge: Cambridge University Press.

Mejía Acosta, Andrés. 2009. Informal Coalitions and Policymaking in Latin America. Routledge: New York.

Mejía Acosta, Andrés y John Polga Hecimovich. 2009. "Parlamentary Solutions to Presidential Crises to Ecuador". En Presidential Crises in Latin America. L. Marsteintredet y M. Llanos (edits.) Palgrave: Basingstoke (en prensa).

Ministerio de Economía y Finanzas. (en línea) http:/ / mef.gov.ec/pls/portal/docs/PAGE/MINISTERIO_ ECONOMIA_FINANZAS_ECUADOR/PUBLICACIONES/BOLETINES_INVERSION_SOCIAL/ BOLETIN_25/ARCHIVOS/4_EVOLUCION_HISTORICA_DE_LA_INVERSION_E_INDICES_DE_ GESTION.PDF (Consulta: 09-09-09).

Morgenstern, Scott y Benito Nacif. 2002. Legislative Politics in Latin America. Cambridge: Cambridge University Press.

Pachano, Simón. 2008. "El precio del poder: izquierda, democracia y clientelismo en Ecuador". Ponencia presentada al Segundo Coloquio Internacional de Ciencia Política Gobiernos de izquierda en Iberoamérica en el siglo XX. Xalapa, Veracruz, México.

Stein, Ernesto y Mariano Tommasi. 2006. (en línea) The Institutional Determinants of State Capabilities in Latin America. http://siteresources.worldbank.org/INTDECABC2006/Resources/Tommasi.PDF (Consulta: 01-09-09).

Sociedad Interamericana de Prensa. (en línea) www.sipiapa.org (Consulta: varios días).

Santiago Basabe Serrano es Doctor en Ciencia Política (Universidad Nacional de San Martín, Buenos Aires-Argentina). Director del Centro de Investigaciones de Política y Economía (CIPEC) y Profesor Agregado de la Facultad Latinoamericana de Ciencias Sociales, FLACSO Sede Ecuador. (sbasabe@ flacso.org.ec)

Simón Pachano es Doctor en Ciencia Política (Universidad de Salamanca). Coordinador del Programa de Estudios Políticos de la Facultad Latinoamericana de Ciencias Sociales, FLACSO Sede Ecuador. (spachano@flacso.org.ec)

Andrés Mejía Acosta es Doctor en Ciencia Política (Notre Dame University). Investigador del Instituto de Estudios para el Desarrollo (IDS) de la Universidad de Sussex, Reino Unido (A.MejiaAcosta@ ids.ac.uk) 
